\title{
UbibusRoute : Um Sistema de Identificação e Sugestão de Rotas de Ônibus Baseado em Informações de Redes Sociais
}

\author{
Vanessa Gomes de Lima ${ }^{1}$, Filipe de Moraes Rêgo Magalhães ${ }^{1}$, Adriano de Oliveira \\ Tito $^{1}$, Rodolfo Arruda dos Santos ${ }^{1}$, Arley Ramalho Rodrigues Ristar ${ }^{1}$, Luana \\ Martins dos Santos ${ }^{1}$, Vaninha Vieira ${ }^{2}$ e Ana Carolina Salgado ${ }^{1}$ \\ ${ }^{1}$ Centro de Informática - Universidade Federal de Pernambuco (UFPE) \\ 50.733-970 - Recife - PE - Brasil \\ ${ }^{2}$ DCC - Universidade Federal da Bahia (UFBA) - Salvador - BA - Brasil \\ $\{\mathrm{vgl} 2, \mathrm{fmrm}, \mathrm{aot}, \operatorname{ras} 7, \operatorname{arrr2}, \operatorname{lms} 7, \mathrm{acs}\}$ @cin.ufpe.br, vaninha@ufba.br
}

\begin{abstract}
User Information Systems of public transport are intended to provide information to passengers and support their decisions. Most systems for this purpose are using static information or aided by GPS transmitters installed in vehicles. The citizens can support the improvement of public service and this can be done, for example, through social networks. This paper presents the UbibusRoute, a mobile system that considers dynamic traffic contextual information from social networks and presents information about routes for users, using the Google Maps API as a source of geolocation and the Twitter API as a provider of information by citizens.
\end{abstract}

\begin{abstract}
Resumo. Sistemas de Informação ao Usuário do transporte coletivo visam fornecer informações aos passageiros e apoiar suas decisões. A maioria dos sistemas com esse propósito utiliza informações estáticas ou auxiliadas por transmissores GPS instalados nos veículos. Os cidadãos podem contribuir com a melhoria dos serviços públicos e isto pode ser feito, por exemplo, com o uso das redes sociais. Este trabalho apresenta o UbibusRoute, um sistema móvel que considera informações contextuais dinâmicas do trânsito provenientes de redes sociais e apresenta informações sobre as rotas aos usuários, utilizando a API do Google Maps, como fonte de geolocalização e a API do Twitter como provedora de informações dos cidadãos.
\end{abstract}

\section{Introdução}

O cenário atual do trânsito nas grandes cidades brasileiras vem piorando a cada dia. Com o aumento do número de carros particulares nas vias, os congestionamentos tornaram-se cada vez mais frequentes. Segundo [Zhang et al. 2011] não será possível melhorar o trânsito alargando ruas, construindo viadutos ou fazendo rodízio de carros. Para isto, é preciso que o poder público e as empresas operadoras do transporte coletivo aprimorem o serviço prestado, a fim de mudar a cultura das pessoas e fidelizá-las ao transporte público [Pilon 2009].

No entanto, há muitos fatores que impedem que algumas parcelas da população optem pela utilização do transporte coletivo urbano e, de acordo com [Cutolo 2003], as principais barreiras são a ausência de informações relativas aos serviços e/ou sua baixa 
qualidade. Como opção de solução de alguns desses problemas surgiram os Sistemas Inteligentes de Transporte (SIT), que consistem na utilização da Tecnologia da Informação e Comunicação (TIC) para subsidiar a infraestrutura do sistema de transporte com o objetivo de buscar melhorias em aspectos referentes ao mesmo [Gómez et al. 2009], tais como: gerenciamento de tráfego e sugestão de rotas aos motoristas; informações aos usuários sobre condições meteorológicas, de estradas, possíveis perigos, locais de incidentes, rotas ótimas e itinerário de veículos; conhecimento sobre o controle de veículos em determinadas situações, sistemas de alertas e colisões.

Existem também os Sistemas Avançados de Transporte Público (SATP), que são aplicações do SIT no apoio ao aumento da eficiência e segurança dos sistemas de transporte público [Sussman 2005]. No contexto dos SATP, encontram-se os Sistemas de Informações aos Usuários (SIU) que constituem em uma importante ferramenta de comunicação entre os operadores/gestores do transporte público e os usuários, pois através destas é possível fornecer aos passageiros, informações que satisfaçam suas necessidades específicas, tais como: horário de chegada dos ônibus nas paradas, tempo de espera, próximo veículo a passar na parada e conselhos de rotas aos usuários [Schein 2003][Pilon 2009].

Em paralelo, o aumento da popularidade dos dispositivos móveis com acesso à Internet e o uso crescente das redes sociais têm contribuído para o surgimento de novos aplicativos que possam atender às diversas necessidades dos usuários. As redes sociais vêm ajudando as pessoas a lidar com seus problemas diários, uma vez que facilitam a troca e o compartilhamento de informações dinâmicas, em tempo real, relacionadas aos mais diversos aspectos do cotidiano, inclusive as situações que envolvem o trânsito. Segundo [Levy 2003], a área de Crowdsourcing (ou inteligência coletiva) incentiva a combinação do conhecimento individual provido por um grupo de pessoas para produzir novas informações ou ideias mais úteis.

Existem vários tipos de aplicativos baseados em localização que fornecem informações aos usuários sobre o trânsito (e.g. Google Maps ${ }^{1}$, [Mazhelis et al. 2011]). Esses aplicativos provêm, em sua maioria, informações sobre rotas e estimativa de tempo de chegada, mas não são totalmente direcionadas aos passageiros de ônibus e não levam em consideração acontecimentos dinâmicos como engarrafamentos, acidentes, alagamentos, entre outros.

O problema, nos casos descritos, é que os passageiros do transporte público não têm um serviço que os apoie na decisão sobre que ônibus e rota tomarem para chegar aos seus destinos, contornando situações de tráfego intenso ou acidentes. Em nosso projeto de pesquisa, denominado Ubibus [Vieira et al. 2011], investigamos o uso de tecnologias relacionadas a dispositivos móveis, web e mídias sociais como apoio aos passageiros de transporte público em grandes e médios centros urbanos. Neste contexto, propomos o UbibusRoute, uma solução direcionada aos usuários de transporte coletivo por ônibus, que usa informações provenientes de redes sociais para recomendar rotas a esses usuários apoiando-os em suas tomadas de decisão. O sistema utiliza como fonte de

\footnotetext{
${ }^{1} \mathrm{http}: / /$ maps.google.com
} 
informações contextuais dinâmicas a rede social Twitter $^{2}$ e a API de geolocalização Google Maps.

O restante desse artigo está organizado da seguinte forma: a Seção 2 descreve o uso de redes sociais e contexto no apoio à recomendação de rotas em sistemas de transporte público inteligente; a Seção 3 descreve alguns trabalhos correlatos ao proposto; a Seção 4 apresenta o sistema UbibusRoute, sua arquitetura e questões técnicas de implementação; a Seção 5 detalha um cenário de uso experimental realizado com o intuito de avaliar o sistema proposto; a Seção 6 discute as contribuições e conclusões alcançadas com essa pesquisa e as perspectivas de trabalhos futuros.

\section{Uso de Contexto e Redes Sociais para Recomendação de Rotas em Sistemas Inteligentes de Transporte}

Segundo [Kharaev 2010] SIT são os próximos grandes desafios da eletrônica automotiva mundial. Diante desta afirmação é necessária a criação de mecanismos que aprimorem seus serviços, enriqueçam sua semântica e provejam funcionalidades que aproximem mais o homem da máquina de maneira transparente.

Contexto computacional pode ser visto com um conjunto de condições e influências relevantes à aplicação e que tornam uma situação única e compreensível [Brézillon 1999]. Através da utilização de elementos contextuais estáticos e/ou dinâmicos, a aplicação pode em circunstâncias diversas, mudar seu comportamento adaptando-se às necessidades atuais.

O transporte coletivo por ônibus tem como características a complexidade e inflexibilidade, impondo rotas de ônibus e horários pré-estabelecidos. Muitas vezes os horários não são respeitados devido a incertezas do trânsito nas grandes cidades, dificultando o planejamento dos deslocamentos por parte do usuário de transporte coletivo. A utilização de informações de contexto neste tipo de aplicação, como por exemplo, informações de redes sociais sobre o trânsito nas vias podem aumentar a medida de desempenho e tornar a aplicação desenvolvida mais adaptativa ao usuário, satisfazendo suas preferências e necessidades.

Desde meados da década de 90 , as redes sociais baseadas na Web vêm sendo desenvolvidas, apresentando ascendente crescimento tanto no número de redes quanto em seus escopos, estas estabelecem relações entre usuários com interesses semelhantes em um mesmo ambiente. Segundo [Golbeck 2005], as redes sociais podem ser vistas como grandes repositórios de dados que armazenam informações sobre seus usuários ou enviadas por eles.

As informações inseridas nas redes sociais por seus usuários podem ser utilizada para gerar conhecimento coletivo dinâmico. Segundo [Dimitrakopoulos 2011] uma das áreas que podem se beneficiar destas informações é a de transportes, uma vez que veículos automotores tornaram-se parte indispensável em nosso cotidiano. Ao utilizar-se destas informações dinamicamente geradas, os sistemas de informações aos usuários do transporte coletivo urbano, podem fornecer informações mais relevantes aos usuários, inclusive para sistemas de recomendação e sugestão de rotas. Segundo [Burke 2002],

\footnotetext{
${ }^{2} \mathrm{http} / / / \mathrm{www} . \mathrm{twitter} . \mathrm{com}$
} 
Sistemas de Recomendação (SR) são aqueles que produzem sugestões individualizadas, ou têm a função de guiar o usuário de forma personalizada, em ambientes onde a quantidade de informação ultrapassa a capacidade de qualquer indivíduo examiná-lo.

Alguns Sistemas Inteligentes de Transporte em funcionamento exibem rotas de ônibus em mapas aos passageiros de transporte coletivo. Estes verificam, em tempo real, a localização do veículo entre os locais apontados pelos usuários como origem e destino. Segundo [Ferris et al. 2010], os usuários de transporte público podem ser divididos em dois grupos: os usuários frequentes e os esporádicos. Para os usuários esporádicos a exibição de rotas é considerada como informação mais importante, haja vista que os mesmos não estão familiarizados com as opções disponíveis. Enquanto que os usuários frequentes se interessam pelas informações dos horários de chegada dos ônibus nas paradas, pois já conhecem a sequência de pontos e itinerários.

Em nossa pesquisa, buscamos atender aos dois grupos de usuários recomendando rotas e fornecendo informações aos passageiros esporádicos e apoiando o planejamento de deslocamentos dos usuários frequentes, fornecendo informações sobre rotas alternativas, que podem ser utilizadas por ocasião de engarrafamentos e/ou impedimentos das vias e atrasos dos ônibus.

\section{Trabalhos Relacionados}

Durante nossas pesquisas encontramos alguns trabalhos que recomendam rotas aos usuários, como [Mazhelis et al. 2011], mas não são voltados ao transporte público. Em [Hoar 2010] e [Ferris et al. 2010], são apresentados sistemas que exibem rotas de ônibus aos usuários, mas não processam dados dinâmicos de redes sociais. A utilização de tipo de dados contextuais é vista em um SIT denominado $W_{a z}{ }^{3}$, mas este não contempla o transporte público por ônibus. Existem ainda algumas propostas, como [Alves et al. 2011], para desenvolvimento de um sistema de recomendação de rotas utilizando inteligência coletiva de redes sociais.

O presente trabalho apresenta um sistema de recomendação de rotas aos usuários de transporte público por ônibus, utilizando dados contextuais dinâmicos oriundos de redes sociais. Este sistema foi desenvolvido para uma plataforma móvel, usando smartphones, e será descrito na próxima seção.

\section{UbibusRoute}

Esta seção descreve a arquitetura e detalhes de implementação do UbibusRoute, um sistema de recomendação de rotas de ônibus por meio de informações contextuais dinâmicas extraídas de redes sociais. $\mathrm{O}$ sistema calcula as possíveis rotas, indicando no mapa o caminho a ser tomado juntamente com as rotas necessárias.

\subsection{Arquitetura}

O UbibusRoute foi projetado em uma arquitetura cliente-servidor (Figura 1) onde o cliente contém um componente chamado Aplicativo Móvel, que pode ser nativo de qualquer sistema operacional móvel que se comunique com o servidor seguindo os padrões fornecidos pelo mesmo.

\footnotetext{
${ }^{3}$ http://www.waze.com/
} 
Existem duas bases de dados principais no sistema, a de Dados Contextuais de Trânsito, e a de Dados Estáticos. Os dados estáticos são paradas, linhas de ônibus e percursos. O Aplicativo Móvel envia uma requisição de dados estáticos e pedido de rota ao servidor, recebendo como resultado a rota e as instruções para percorrê-la. Já o módulo Servidor é dividido em três componentes principais: o Identificador de Rotas, responsável por identificar todas as rotas possíveis de acordo com a localização ou parada de ônibus selecionada; Indicador de Rotas, responsável por selecionar a melhor rota de acordo com a preferência do usuário (tempo, preço ou distância); e o Extrator de Informações Contextuais que colhe informações de redes sociais e verifica como o trânsito está naquele momento.

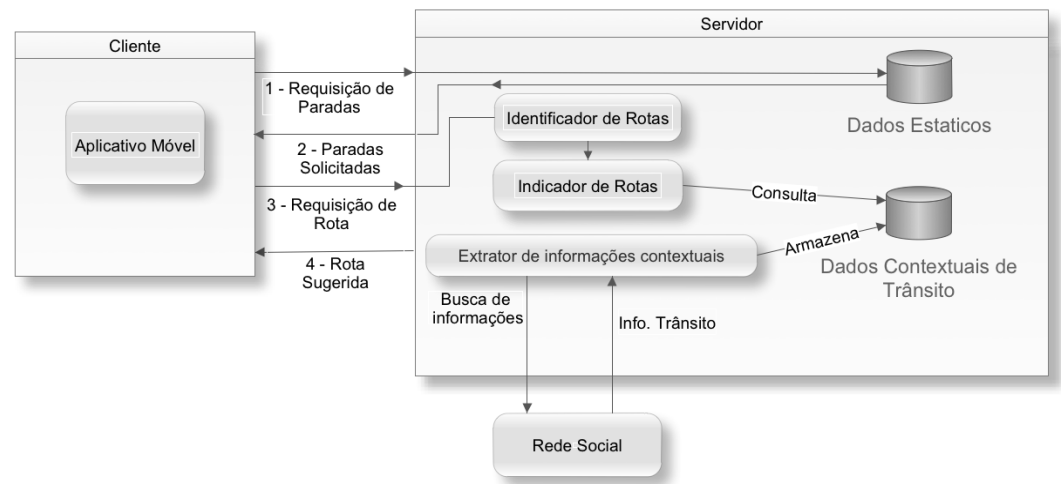

Figura 1. Arquitetura geral do UbibusRoute.

\subsubsection{Aplicativo Móvel}

O cliente, na arquitetura, contém um módulo chamado Aplicativo Móvel, que é a interface com o usuário. $\mathrm{Na}$ execução do aplicativo, é realizada inicialmente uma requisição automática de dados das paradas de ônibus, sendo fornecido ao usuário um mapa onde o mesmo pode visualizar todas as paradas de ônibus disponíveis e selecionar duas: uma parada de ônibus como origem e outra como destino. Além disso, o usuário deve informar se prefere que a rota sugerida seja baseada em alguns fatores como: menor preço, viagem com menor tempo ou menor distância percorrida. Os dados das paradas de ônibus selecionadas, bem como o tipo de viagem escolhido, serão enviados para o Identificador de Rotas no servidor.

A resposta obtida do servidor tem características visuais e textuais, onde consta uma rota traçada em um mapa, enfatizando o ponto de origem, o ponto de destino, os pontos de troca de ônibus (caso existam), o preço de cada um deles e uma mensagem textual. Tal visualização segue de acordo a opção selecionada pelo usuário inicialmente, contendo a distância total informada, o preço total a ser gasto, ou ainda o tempo total de viagem. Na resposta textual, o usuário verifica um texto explicando todas as etapas que o passageiro deve seguir para chegar ao seu destino.

\subsubsection{Identificador de Rotas}

O processo de identificar rotas, que acontece no componente Identificador de Rotas, é iniciado a partir de uma requisição por parte do Aplicativo Móvel. Desenvolveu-se um 
algoritmo de busca de rotas modificando o algoritmo guloso de Dijkstra ${ }^{4}$ para que seja retornado o menor caminho, levando em consideração o parâmetro vindo do Aplicativo Móvel, ou seja, o menor caminho não é sempre pela distância; a depender do parâmetro, o peso das arestas do grafo que o algoritmo Dijkstra gerencia muda de acordo com a preferência do usuário. A função do algoritmo desenvolvido é, desse modo, procurar os possíveis caminhos que possam ser traçados entre a origem e o destino, oferecendo como saída essas rotas com parâmetros que indicam preço da viagem, distância a ser percorrida e tempo total. Este módulo classifica, então, cada possível rota com três pontuações numéricas: uma para a distância, uma para o tempo e uma para o preço a ser gasto. A saída desse módulo é enviada ao Indicador de Rotas.

\subsubsection{Indicador de Rotas}

O componente Indicador de Rotas, por sua vez, utiliza todas as rotas possíveis, recuperadas a partir do processo de identificação, e seleciona a melhor, baseada na preferência inicial definida pelo usuário (menor preço, menor distância ou menor tempo). Esta seleção é feita a partir da saída das rotas repassadas do módulo Identificador de Rotas; como cada rota possui uma pontuação de tempo, custo de preço, e distância, é escolhida a que contém o menor valor do parâmetro indicado pelo usuário. Este componente consulta, também, informações contextuais armazenadas pelo Extrator de Informações Contextuais, que estão guardadas na base de Dados Contextuais, provenientes de redes sociais. Sendo assim, o Indicador de Rotas é responsável por cruzar as preferências do usuário com as informações contextuais capturadas das redes sociais, atribuindo uma nova pontuação relativa ao tempo para as possíveis rotas.

\subsubsection{Extrator de Informações Contextuais, Dados Contextuais e Redes Sociais}

O objetivo do Extrator de Informações Contextuais é capturar informações dinâmicas de Redes Sociais. É possível obter mensagens recentes relacionadas aos trechos do trânsito por onde passam as linhas de ônibus cadastradas no UbibusRoute.

A rede social explorada no UbibusRoute foi o Twitter, devido à natureza curta de suas mensagens, com no máximo 140 caracteres. O módulo das Redes Sociais está intrinsecamente ligado ao Extrator de Informações Contextuais. Os tweets são extraídos a cada 20 minutos, - tempo considerado como bom para atualização de uma nova quantidade de tweets relacionados ao trânsito -, tratados utilizando expressões regulares e armazenados em uma Base de Dados Contextuais de Trânsito, localizada no servidor. Tais informações são utilizadas para conhecer a situação atual do trânsito.

As mensagens provenientes das redes sociais precisam estar em um formato préestabelecido, a fim de identificar a informação. Essa limitação pode acabar por excluir outras mensagens que contenham informações importantes e relevantes sobre o trânsito. No entanto, tendo as mensagens nesse formato pré-definido, há um ganho de velocidade no processo de identificação textual das diversas situações de trânsito, melhorando o desempenho e garantido corretude na informação identificada.

Foi desenvolvida, então, uma gramática de reconhecimento e padronização das mensagens. As mensagens devem ser compostas por um número que identifica as horas,

\footnotetext{
${ }^{4}$ Dijkstra Algorithm <http://www.cs.auckland.ac.nz/ jmor159/PLDS210/dijkstra.html>.
} 
$<H O R A>$, os minutos $\langle M I N>$, um agravante $<A G R A V A N T E\rangle$, que é uma palavra que intensifica uma situação de trânsito (a presença de um agravante na mensagem a ser identificada é facultativa). Uma situação de trânsito $<S I T U A C ̧ A \tilde{O} O\rangle$, por sua vez, é uma palavra que indica congestionamento ou fluidez no trânsito, em diferentes níveis. Uma preposição <PREPOSIÇÃ $O>$ é apenas um conector entre a situação de trânsito e a localidade da ocorrência, composta por $<$ LOCAL $>$ e $<$ TRECHO $>$. A gramática proposta é ilustrada na Figura 2.

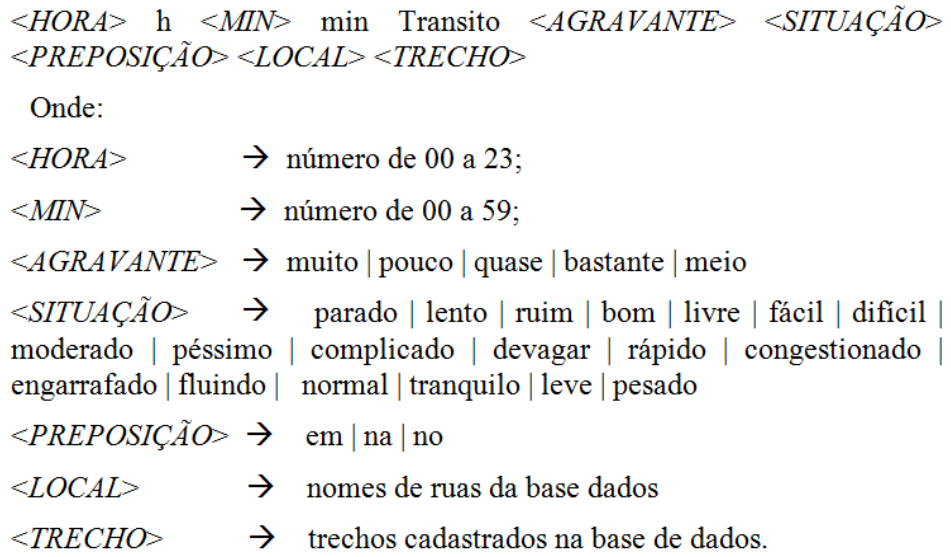

Figura 2. Gramática para Extração de Mensagens de Trânsito de Redes Sociais.

Toda informação que é obtida a partir do processo de identificação do Extrator de Informações Contextuais é armazenada na base de Dados Contextuais de Trânsito, mas não a mensagem pura extraída do Twitter. As informações contextuais extraídas são armazenadas na base de dados como um tipo composto [localização geográfica, dia, horário, pontuação]. A pontuação, que será detalhada na próxima seção, indica o grau de congestionamento de determinado local.

\subsection{Aspectos de Implementação}

O Aplicativo Móvel foi desenvolvido sobre a plataforma Android ${ }^{5}$, em Java ${ }^{6}$ e usando alguns recursos da API do Google Maps. A comunicação com o Servidor é feita seguindo os princípios $\operatorname{REST}^{7}$ (Representational State Transfer), onde o módulo Cliente faz uma requisição HTTP, contendo origem, destino e tipo de busca, e o módulo Servidor responde com um objeto $\mathrm{JSON}^{8}$ (JavaScript Object Notation).

O servidor do UbibusRoute foi implementado com o framework Django ${ }^{9}$ e todos os seus módulos foram desenvolvidos em Python ${ }^{10}$. A resposta do servidor ao Aplicativo Móvel é dada a partir da interação entre os componentes: Identificador de Rotas e Indicador de Rota, consultando os Dados Contextuais de Trânsito. Tal resposta possui vários parâmetros como: pontos geográficos da origem e destino, dados geográficos das paradas onde houver troca de ônibus; preço de cada troca de ônibus, caso exista; mensagem de resposta textual; e a mensagem final da requisição, que

\footnotetext{
${ }^{5} \mathrm{http}: / / \mathrm{www}$.android.com/

${ }^{6} \mathrm{http}: / /$ www.java.com/

${ }^{7} \mathrm{http}: / /$ rest.elkstein.org/

${ }^{8} \mathrm{http}: / /$ www.json.org/

${ }^{9} \mathrm{https} / / /$ www.djangoproject.com/

${ }^{10} \mathrm{http}: / /$ python.org/
} 
contém: a distância a ser percorrida, custo de tempo total da viagem, ou o custo relativo ao preço.

A comunicação com o Twitter é realizada pelo Extrator de Informações Contextuais por meio da API REST ${ }^{11}$ do Twitter. Isto permite acesso a dados essenciais como: tweets (mensagens postadas pelos usuários), prazos de atualização e informações dos usuários. A atualização dos dados contextuais de trânsito ocorre de acordo com a atual situação de trânsito informada pelos tweets.

Para manter os dados atualizados sobre o estado atual do trânsito, foi desenvolvido um crawler (componente que busca continuamente os tweets relativos ao trânsito), que se encontra dentro do Extrator de Informações Contextuais. Este crawler utiliza a API REST do Twitter e captura automaticamente as informações do perfil @Ubibus_PE de acordo com dois parâmetros: quantidade máxima de tweets por captura - definida como 20, para efeitos de desempenho; e a diferença entre os instantes de tempo atual e de criação do tweet - definido como 20 minutos na versão atual (podendo ser parametrizado em versões futuras). Com isso, é possível obter os 20 últimos tweets que foram publicados no perfil.

Também foi construído um script em Python que formata o conteúdo capturado do perfil do Twitter, extraindo o trecho e a situação atual do trânsito. Este script contém um algoritmo de interpretação de informações de trânsito que opera considerando a Gramática definida anteriormente (Seção 4.1.4). A situação do trânsito é calculada de acordo com algumas variáveis que classificam o adjetivo <SITUAÇÃ $O>$ combinado com o seu <AGRAVANTE> . De acordo com a situação e a presença ou não de um agravante é calculada uma pontuação para aquele endereço; essa pontuação é válida por 20 minutos, (tempo considerado suficiente para mudança na fluidez do tráfego). Para facilitar a extração das informações do trânsito, foi criado um conjunto de classificação das situações e dos agravantes. A situação pode estar classificada como [bom, médio e ruim] e os agravantes como [alto, baixo].

Toda rua que é representada na base de dados possui, estaticamente, um indicativo de velocidade da via. O cálculo no tempo de trânsito (a pontuação) é calculado em função da mudança que pode ocorrer nessa velocidade. Uma vez que o trânsito está livre (sem interrupções ou congestionamentos), a velocidade não é alterada, portanto a pontuação fica zerada.

Na primeira versão deste sistema, o retorno desse algoritmo consiste de uma pontuação que oscila de 0 a 3 onde: 0 (zero) indica que o trânsito está livre, como descrito anteriormente; 1 (um) indica que o trânsito está moderado, quando houve detecção dos classificadores de situação médio; quando da detecção do classificador ruim, a pontuação atribuída é 2 (dois) e indica que o trânsito está lento; e, por fim, 3 (três) indica que o trânsito está muito lento, quando da junção do classificador ruim com o agravante alto. Posteriormente, estes números são utilizados no algoritmo de busca de rotas para influenciar na decisão de qual rota sugerir e qual tempo informar ao usuário.

\footnotetext{
${ }^{11}$ Twitter, API REST. <http://dev.twitter.com/docs/api>
} 


\section{Cenário de Uso do UbibusRoute}

A plataforma para experimentação do sistema teve como objetivo verificar se o mesmo se comportava de acordo com as informações contextuais dinâmicas extraídas da rede social utilizada. Tal plataforma foi inicialmente concebida com uma base de dados simulada e criação de um perfil no Twitter (@Ubibus_PE) para as postagens das mensagens de trânsito. A seguir, será descrito um cenário de uso do UbibusRoute, simulando algumas paradas de ônibus com latitude, longitude e um nome identificador. Também foram simuladas linhas de ônibus possuindo preços e rotas - todas situadas na cidade do Recife. Ao iniciar a aplicação estará disponível ao usuário a tela com as várias paradas de ônibus (Figura 3). Será considerado o caso em que o usuário escolhe a parada cujo identificador é EC como origem e LSO1 como destino.

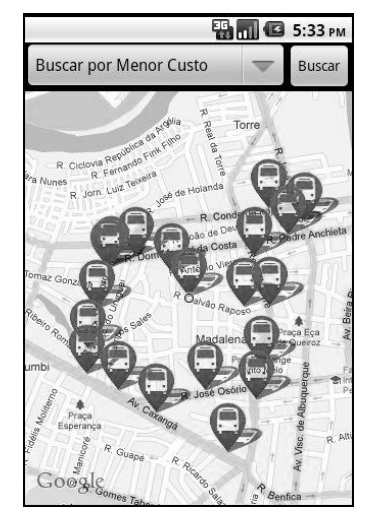

Figura 3 - Mapa com as paradas cadastradas no sistema.

Entre EC e LSO1 é possível ter rotas com distâncias e preços de passagens distintas, bem como pegar ônibus diferentes, e a frequência com que estes veículos passam pelas paradas também é diferente. Observar-se na Figura 4 a parada EC destacada mais à esquerda e a $L S 01$ destacada mais à direita, existindo dois caminhos possíveis entre elas: o primeiro é seguindo pela Rua José Osório, cuja distância é de aproximadamente $760 \mathrm{~m}$, e o segundo pela Rua Real da Torre e em seguida Avenida Caxangá, cuja distância é de aproximadamente $1300 \mathrm{~m}$. Com as paradas de origem e destino selecionadas, o usuário poderá escolher o tipo de busca de acordo com suas preferências. Neste caso, foi selecionada a "Busca por Menor Tempo", que resulta em um menor tempo de viagem (Figura 4). Essa busca foi realizada sem que nenhuma informação sobre o trânsito tenha sido postada no perfil @Ubibus_PE do Twitter.

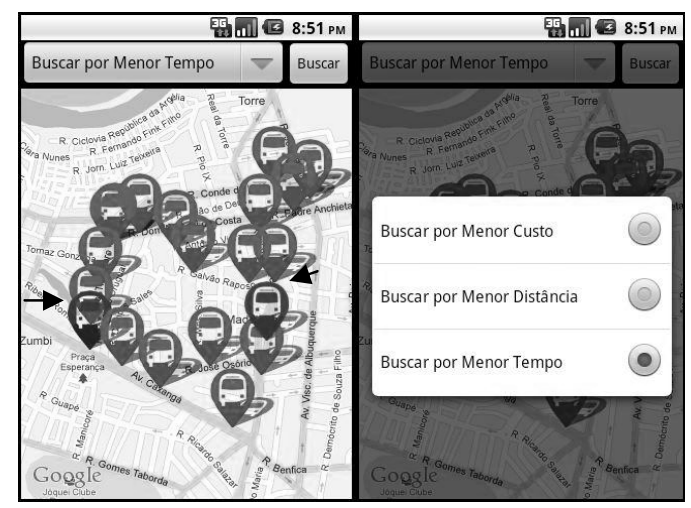

Figura 4 - Mapa com paradas escolhidas em destaque e possíveis escolhas de rota. 
Após realizar a busca, o UbibusRoute exibe ao usuário a rota escolhida e as informações necessárias como: a linha de ônibus escolhida; preço da tarifa; as paradas que foram anteriormente selecionadas e o tempo total do deslocamento (Figura 5). A rota escolhida indica ao usuário que pegue o ônibus 201 na sua parada de origem e vá até a parada de destino, sem troca de ônibus, pela Rua José Osório. Essa rota foi escolhida por que não há informações de alteração de trânsito em nenhuma das rotas possíveis. Então, foi considerada a velocidade média das vias, o caminho mais próximo e a maior frequência de circulação dos ônibus pelas paradas. Nota-se, que o tempo total gasto na viagem foi de 11 minutos.

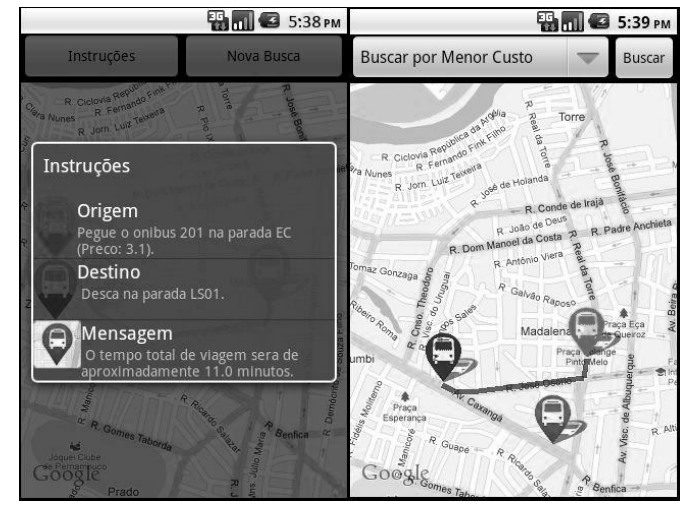

Figura 5 - Mapa e informações da rota indicada.

Para uma melhor compreensão da influência da informação contextual dinâmica, foram publicados tweets de trânsito engarrafado na Rua José Osório (Figura 6) que faz parte da rota anteriormente mostrada.

\section{ubibus_pe Ubibus Pernambuco \\ 18h13min Transito muito engarrafado na Rua Jose Osorio \\ 18 hours ago}

\section{Figura 6- Tweet de Informação de Trânsito}

Ao refazer a busca com a mesma parada de origem e destino e o tipo de busca realizada anteriormente, verificamos que o sistema levou em consideração a informação colhida do tweet indicando outra rota com a linha de ônibus 101, diferente da sugerida anteriormente, não passando pela Rua José Osório que está engarrafada (Figura 7).

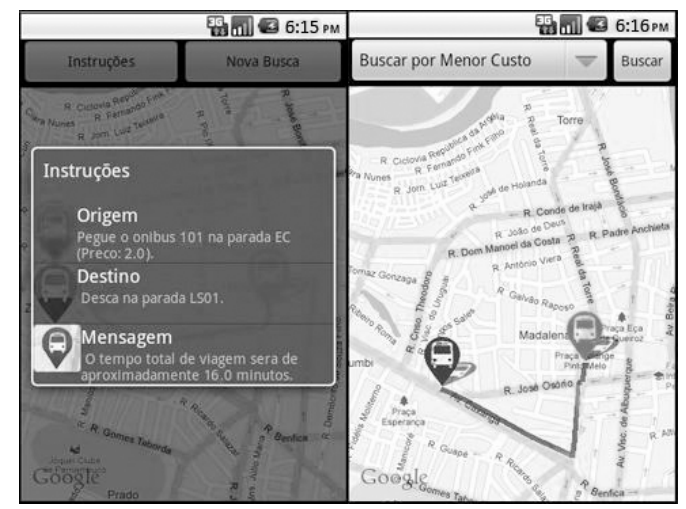

Figura 7 - Mudança na rota Sugerida 
De acordo com o cenário descrito, o sistema proposto obteve resultados satisfatórios, seguindo os elementos contextuais dinâmicos colhidos no Twitter, e indicando ao usuário a melhor rota para o seu deslocamento, de acordo com o tipo de busca selecionada pelo passageiro.

\section{Conclusão}

Atualmente os Sistemas Inteligentes de Transporte se transformaram em uma alternativa atrativa e muito viável para solucionar alguns problemas e superar desafios na área de transporte das grandes cidades, essa evolução se deve em parte ao acelerado crescimento da Tecnologia da Informação e Comunicação. Tal evolução contribui para a crescente utilização de sistemas computacionais em praticamente todas as áreas da atividade humana. Sendo assim, há uma ascendente procura por sistemas dinâmicos e sensíveis ao contexto. A utilização deste tipo de aplicação no provimento de informações aos usuários de transporte público urbano, podem proporcionar maior atração e fidelização ao serviço.

Este trabalho teve por objetivo desenvolver uma aplicação móvel para indicar e sugerir rotas aos usuários de transporte público, capaz de obter informações contextuais dinâmicas da rede social Twitter. Tal recomendação é baseada em pontos de origem, destino e tipo de busca, fornecidos pelos usuários. Para implementação do UbibusRoute foram utilizadas ferramentas externas como a API do Google Maps e Twitter. O aplicativo mostrou que é possível recomendar rotas de ônibus aos usuários utilizando informações dinâmicas de redes sociais, apesar de demandar algumas melhorias que serão abordadas em pesquisas futuras.

Alguns trabalhos futuros serão investigados com o intuito de contribuir para a melhoria do sistema desenvolvido, entre eles podemos citar: a implementação de outros algoritmos para a busca por menor preço, pois o algoritmo de Dijkstra, por ser guloso, não dá o resultado desejado. Uma das razões é o fato de levarmos em consideração as trocas de ônibus e frequência dos ônibus, o que não pode ser especificado somente com o algoritmo de Dijkstra, pois ele não possui nenhum método heurístico. Outros pontos a serem considerados são: utilizar uma base de dados reais, a fim de realizar testes mais realistas e precisos; expandir o tratamento das redes sociais para permitir capturar informações de trânsito provenientes de outros perfis e sites; e evoluir o algoritmo de interpretação de informações de trânsito, a fim de realizar análise semântica.

\section{Referências Bibliográficas}

Alves, L. P. S., Chaves, A. P e Steinmacher, I. F. (2011) "Um aplicativo baseado em inteligência coletiva para compartilhamento de rotas em redes sociais". In: VIII Simpósio Brasileiro de Sistemas Colaborativos (SBSC), Paraty-RJ.

Brézillon, P. (1999) "Context in Artificial Intelligence: IA Survey of the Literature", Computer \& Artificial Intelligence, v. 18, pp. 321-340.

Burke, R. (2002) "Hybrid Recommender Systems: Survey and Experiments", User Modelling and User-Adapted Interaction, pp. 331-370.

Cutolo, F. A. (2003) "Diretrizes para sistema de informação ao usuário". In: III Seminário Internacional PROMOTEO, Porto Alegre-RS. 
Dimitrakopoulos, G. (2011) "Intelligent transportation systems based on internetconnected vehicles: Fundamental research areas and challenges", ITS Telecommunications (ITST), 11th International Conference, pp. 145-151.

Ferris, B., Watkins, K. and Borning, A. (2010) "Location-Aware Tools for Improving Public Transit Usability", IEEE Pervasive Computing, v. 9 n. 1, pp. 13-19.

Golbeck, J. (2005) "Computing and Applying Trust in Web-Based Social Networks". $184 \mathrm{f}$. Thesis (Doctor of Philosophy) - University of Maryland, College Park, MD, USA.

Gómez, A., Diaz, G. and Bousetta, K. (2009) "ITS Forecast: GIS Integration with Active Sensory System". In: Information Infrastructure Symposium, G1JS'09. Global, pp. 1-6.

Hoar, R. (2010) "A Personalized Web Based Public Transit Information System with User Feedback". In: 13th International IEEE Conference on Intelligent Transportation Systems, Portugal.

Kharaev, V. (2010) "Comparative Analysis of Mobile Telecommunication Technologies for Intelligent Transport Systems”. Irkutsk Listvyanka, Russia.

Levy, P. (2003), “A Inteligência Coletiva”. São Paulo: Loyola.

Mazhelis, O., Zliobaite, I. and Pechenizkiy, M. (2011) "Context-aware personal route recognition". In: The Fourteenth International Conference on Discovery Science (DS 2011), Espoo, Finland, pp. 365-379.

Pilon, J. A. (2009) "Sistema de Informação ao Usuário do Transporte Coletivo por Ônibus na Cidade de Vitória-ES”. 125 f. Dissertação (Pós-Graduação em Engenharia de Produção) - Universidade Tecnológica Federal do Paraná - Ponta Grossa-PR.

Schein, A. L. (2003) "Sistema de Informação ao usuário como estratégia de fidelização e atração". 148 f. Dissertação (Mestre em Engenharia de Produção) - Departamento de Engenharia de Produção, Universidade Federal do Rio Grande do Sul, Porto Alegre -RS.

Sussman, J. (2005), "Perspectives on Intelligent Transportation Systems". New York, USA: Springer.

Vieira, V., Caldas, and L. R. Salgado, A.C. (2011) "Towards an ubiquitous and context sensitive public transportation system". In 4th International Conference on Ubimedia Computing, São Paulo-SP.

Zhang, J., Wang, F., Wang, K., Lin, W., Xu, X. and Chen, C. (2011) "Data-Driven Intelligent Transportation Systems: A Survey", In: IEEE Transactions on Intelligent Transportation Systems. vol. 12, no. 4, pp. 1624-1639. 